\title{
NBOMe Compounds: Systematic Review and Data Crunching of the Surface Web
}

\author{
Ahmed Al-Imam ${ }^{1,2} \&$ Ban A. AbdulMajeed ${ }^{3}$ \\ ${ }^{1}$ Department of Postgraduate Medicine, School of Life and Medical Sciences, University of Hertfordshire, United \\ Kingdom \\ ${ }^{2}$ Department of Anatomy and Cellular Biology, College of Medicine, University of Baghdad, Iraq \\ ${ }^{3}$ Department of Pathology and Forensic Medicine, College of Medicine, Al-Nahrain University, Iraq \\ Correspondence: Dr Ahmed Al-Imam, House 18/5, Al-Akhtal Street, District 318, Al-Adhamyia, 10053, Baghdad, \\ Iraq. E-mail: tesla1452@gmail.com; a.m.al-imam@herts.ac.uk
}

Received: July 25, 2017 Accepted: August 17, 2017 Online Published: September 18, 2017

doi:10.5539/gjhs.v9n11p126

URL: https://doi.org/10.5539/gjhs.v9n11p126

\begin{abstract}
Background: NBOMe compounds, some of which commercially known as "N-Bomb" or "Smiles" signifying their potency, represent a uniquely potent group of phenethylamine derivatives. These have been recently used in the past decade for their powerful hallucinogenic properties to induce a "psychedelic trip".

Methods: This study is an analytics of the surface web incorporating data from; the published literature, grey literature, drug fora, and trends' databases. The study aims to review the pharmacodynamic effects of three most popular N-Bombs $(25 \mathrm{~b}, 25 \mathrm{c}$, and $25 \mathrm{i})$, analyse reported cases of intoxications and fatalities, and correlate these incidents with data retrieved from Google Trends.

Results: The potency and popularity of NBOMe compounds are tallied worldwide, 25b-NBOMe (least potent and least popular), 25i-NBOMe (most potent and most popular), while the $25 \mathrm{c}-\mathrm{NBOMe}$ is in the middle. The popularity of each has been on the rise since 2011-2012, these compounds are most popular in the United States and the United Kingdom, while data from the developing world and the densely-populated India and China are either lacking or inadequate. The reported cases of intoxications and deaths were statistically proven to be correlated with the trends' data

Conclusion: Inferential statistical information has associated cases of $\mathrm{NBOMe}(\mathrm{s})$ ' morbidities-mortalities with the public interest of surface web users in these hallucinogens. This study can serve a blueprint for an early warning system to be activated based on changes in trends' data.
\end{abstract}

Keywords: Novel Psychoactive Substance, NPS, sympathomimetic, phenethylamines, Bath Salts, NBOMe; N-Bomb, Serotonin, 5-HT2 Receptor Agonists, Hallucinogens, psychedelics, epidemiology, Google Trends

\section{Background}

Novel psychoactive substances (NPS), also known as designer drugs or "research chemicals", impose a major health risk and an economic threat worldwide (Al-Imam et al. 2016; Al-Imam, 2017a; Al-Imam et al., 2017). The extent of this phenomenon has been escalating logarithmically and simultaneously together with the growth of the information and communication technologies embodied in the "internet of things", social communication media, online drug fora, and the electronic commerce (e-commerce) phenomenon (DrugWiseUK, 2016; NEPTUNE, 2016; UNODC, 2016). NBOMe compounds, some of which commercially known as "N-Bomb" or "Smiles" signifying their potency, are a uniquely potent group of phenethylamine derivatives. These have been recently used in the past decade for their powerful hallucinogenic effects to induce a "psychedelic trip"; these chemicals belong to a category of NPS known as hallucinogens (Drugfreeworld.org, 2016; UNODC, 2016; Wood et al., 2015). NBOMe compounds were discovered by Ralf Heim in 2003 while he was researching for a pharmacological tool to study the 5-HT2A receptors. Before that point in time, these drugs had no history of human use in addition to the total absence of medical applications till this very moment (Heim, 2004; Wood et al., 2015). The 25X-NBOMe series are substituted phenethylamine compounds, the most common 25b-NBOMe, 25c-NBOMe, and 25i-NBOMe, all have been detected in Europe since 2011 (Wood et al., 2015). 
The available published data on NBOMe compounds are non-representative from an epidemiologic perspective. However, in 2013 the Global Drugs Survey reported that 25i-NBOMe was the most commonly (ab)used. It is also the most potent NBOMe, hence the name "N-Bomb"; these data were also concordant with data from trends databases (Google Trends, 2016). In September 2014, the United Nations Office on Drugs and Crime (UNODC) reported that $25 \mathrm{i}-\mathrm{NBOMe}$ was the most frequently reported NPS, accounting for $43 \%$ of all cases reported worldwide (Wood et al., 2015).

All NBOMe compounds, particularly the 25i-NBOMe, are super potent 5-HT type-2A receptor agonists. Therefore, a typical (ab)user can experience a psychedelic effect in the milligramme range or even less, making it almost as potent as another potent hallucinogenic compound known as lysergic acid diethylamide (LSD) (Andreasen et al., 2015; Byard et al., 2016; Kueppers \& Cooke, 2015; Lowe et al., 2015; Poklis et al., 2014). In fact, NBOMe products are promoted as a "legal alternative of LSD" (Bersani et al., 2014; Nikolaou et al., 2015; Wood et al., 2015), although NBOMe blotters taste distinct from LSD blotters (Psychonautwiki.org, 2016; Reddit.com, DrugsAMA, 2016). It is sold to users in the form of blotting papers (blotters), powder, and liquid form (Bluelight.org, 2016; Wood et al., 2015). These are most commonly administered via oral, buccal or sublingual ingestion, nasal insufflation, intravenous and intramuscular injections, per vaginal and per rectal administration, and freebase smoking (Bersani, 2014; Bluelight.org, 2016; Forrester, 2014; Wood et al., 2015).

The pharmacodynamics are very similar for the three forms of NBOMe; the main difference is the potency which is determined by the affinity towards the 5HT receptors. The most commonly reported features of intoxication are induced by the activation of the serotoninergic pathway and the sympathetic nervous system, resulting in a status of hyper-stimulation of all body systems specifically the cardiopulmonary and nervous system. Hence users are frequently apprehended in a state of agitation, aggression, hyperventilation, increased physical strength, and clouded consciousness or a psychotic-like state (Bersani et al., 2014; Forrester, 2014; Gee, 2015; Hill et al., 2014; Nikolaou et al., 2015; Rose, et al., 2015; Suzuki et al., 2014; Wood et al., 2015).

There have been some sporadically reported cases of intoxication, suicidal attempts, and fatalities. These possibly represent the "tip of the iceberg". Almost all were attributed to the most potent form (the $25 \mathrm{i}$ variant). These catastrophic incidents have been reported highly in the developed world including the United States, United Kingdom, Australia, Canada, China, Denmark, Netherlands, other European countries (Andreasen et al., 2015; Byard et al., 2016; Kueppers \& Cooke, 2015; Lowe et al., 2015; Poklis et al., 2014; Rose et al., 2013; Shanks et al., 2015; Suzuki et al., 2014; Tang et al., 2014; Walterscheid et al., 2014). In the published literature, there are no verifiable reports of intoxication and/or fatality from the developing world.

This study aims to infer an estimation concerning the epidemiologic magnitude of the NBOMe phenomenon based on data retrieved from trends databases, case series, case reports, review articles, and online drug fora. To date, there have been no studies to deploy the use of inferential statistics to describe these trends or the shift in trends of NBOMe compounds.

\section{Materials and Methods}

This is an analytic study of the surface web, cross-sectional and retrospective in nature; it was conducted from October 2016 to January 2017. The study aims were; to review the pharmacodynamic effects of three most popular NBOMes (25b, 25c, and 25i), to analyse reported cases of intoxications-fatalities, and to correlate these with data from Google Trends (Google, Google Trends, 2016), online drug fora, social communication media, and the media networks.

The literature review was carried out using a pre-designed keywords' list; these keywords were allocated into four main themes including; nomenclature and synonyms of NBOMe (1), intoxications and fatalities (2 and 3), and geographical distribution (4). The total number of the individual keywords was 115, truncation and Boolean operators (AND, OR) were also implemented to either make the search more precise (narrow it down) or maximise (expand) the yield of the literature search process (Spink and Ozmultu, 2003). These keywords were highly relevant to the Medical Subject Headings (MeSH) from the NCBI databases (The National Center for Biotechnology Information, 2016). This methodology was carried out in a systematic way across medical and paramedical databases including NCBI-PubMed/Medline, EMBASE, the Cochrane Library, Scopus, EBSCOCINAHL, Web of Science, ResearchGate, OpenGrey, and Google Scholar.

A preliminary (pilot) analysis of the published literature on PubMed-Medline showed that the total number of published studies on NBOMe chemicals barely exceeded a hundred records ( $\mathrm{n}=108$, on the $1^{\text {st }}$ of January-2017). There was a complete absence of manuscripts with high level-of-evidence including systematic reviews and meta-analyses, randomised controlled trials (RCTs), and a total lack of experimental-physiologic trials and 
well-structured cohort studies. Given this dearth of published literature in relation to incidents of intoxications and/or deaths from the developing world, additional data was consulted from unpublished (grey) literature and trends databases including Google trends (Google, Google Trends, 2016). The explored grey databases also included the online drug fora, in addition to social communication media, and media networks (Bluelight.org, 2016; Drugs-forum.com, 2016; Erowid.org, 2016; Officialbenzofury.net, 2016; Reddit.com, 2016). These drug fora and social media networks were analysed using keywords related to NBOMe products-of-interest, relevant threads were further filtered by date and geographic locations. The final displayed threads dealt with cases of users' experiences, adverse effects (reactions), intoxications, disabilities, and fatalities.

Google trends engine was also searched using three keywords "25b-nbome", "26c-nbome", and "25i-nbome" (Google trends, 2016). This design was used to retrieve data on the trends of NBOMe popularity worldwide and in three distinct geographic locations including the United Kingdom (UK), the United States (US), and Australia. The rationale was to choose leading countries of the highest population and from the developed world, in order to infer which of these countries contribute the most to the global (worldwide) NBOMe trends, and to correlate incidents of intoxications and fatalities mostly reported by these developed countries. The aim was to create a digital database representative to the popularity of NBOMe products as searched by the internet (surface web) users. In doing so, the purpose was to infer an estimate on the diffusion and the "electronic epidemiology" of the NBOMe phenomenon and the change in these trends for the past five years (2012-2016). Inferential statistics were conducted using the t-test, ANOVA test, and regression models. These tests were carried out using the statistical package for social science version 20 (SPSS v.20) and Microsoft Excel 2016. There were also arduous attempts to detect a pattern of correlation using data crunching and regression models by correlating the reported cases of intoxications and fatalities with the data reclaimed from Google trends.

\section{Results and Discussion}

\subsection{Critical Appraisal and Evidence-Based Analysis of Bibliography}

The critical appraisal of individual studies was done using the CASP appraisal tools (Better Value Healthcare Ltd, CASP-UK, 2016), and the critical appraisal tools of the Oxford Centre for Evidence-based Medicine (Oxford Centre for Evidence-based Medicine, 2009). Manuscripts and resources of the highest attainable level-of-evidence (Table 1) were used to backup this study, although, the majority of these ranked as either level-4 or level-5 in accordance with classification system implied by the Oxford Centre for Evidence-based Medicine. These studies were case reports $(16.7 \%)$, case series $(7.4 \%)$, and review articles $(11.1 \%)$. There were no systematic reviews $(0 \%)$, nor RCTs on NBOMe $(0 \%)$. One experimental study was found $(1.85 \%)$ which was the original study of Ralf Heim (Heim, 2014). Much of the data were retrieved from online drug fora (31.5\%), high-quality and valuable data were also extracted from trends' databases. Data from systematic reviews and RCTs, written on topics pertinent to NBOMe, were also used in the citation of this manuscript (1.85\%), and from observational studies including cross-sectional and cohort studies (7.4\%). Most of the bibliographic materials were published in the past five years (92.6\%). The overall level-of-evidence of appraised resource materials was in the range of level-5 to level-1b, although the majority of these were either level-3b, 4, or 5. The level-of-evidence of this study itself is estimated to be of level-2b (Oxford Centre for Evidence-based Medicine, 2009). 
Table 1. Analysis of Bibliographic Materials and Resources.

\begin{tabular}{|c|c|c|c|c|c|c|c|c|c|}
\hline References & $\begin{array}{l}\text { Systematic } \\
\text { Reviews } \\
\text { and RCTs }\end{array}$ & $\begin{array}{l}\text { Cross-Sectional } \\
\text { and Cohorts }\end{array}$ & Reviews & $\begin{array}{l}\text { Case } \\
\text { Series }\end{array}$ & $\begin{array}{l}\text { Case } \\
\text { Reports }\end{array}$ & $\begin{array}{l}\text { Drug } \\
\text { Fora }\end{array}$ & $\begin{array}{l}\text { Trends' } \\
\text { Databases }\end{array}$ & Web & Others \\
\hline Before 2012 & 0 & 0 & 1 & 0 & 0 & 0 & 0 & 2 & $1 *$ \\
\hline After 2012 & 1 & 4 & 5 & 4 & 9 & 17 & 2 & 8 & 0 \\
\hline Total & 1 & 4 & 6 & 4 & 9 & 17 & 2 & 10 & 1 \\
\hline Percentage (\%) & 1.85 & 7.4 & 11.1 & 7.4 & 16.7 & 31.5 & 3.7 & 18.5 & 1.85 \\
\hline Cumulative \% & 1.85 & 9.25 & 20.35 & 27.74 & 44.45 & 75.95 & 79.65 & 98.15 & 100 \\
\hline Grand Total & 54 & & & & & & & & \\
\hline Level-of-Evidence $\Omega$ & $1 \mathrm{~b}$ & $3 \mathrm{~b}$ to 4 & $2 b$ & 4 & 5 & N/A & N/A & N/A & 5 \\
\hline Overall Evidence & Level-5 to L & el-1b & & & & & & & \\
\hline
\end{tabular}

* Doctorate thesis by Ralf Heim (Heim, 2014).

$\Omega$ According to the system imposed by the Oxford Centre for Evidence-based Medicine (Oxford Centre for Evidence-based Medicine, 2009).

\subsection{Trends in Nbome Users' Interest}

Valuable data were retrieved from Google trends database; filters were used for; search terms ("25b-nbome", "25c-nbome", and "25i-nbome"), time ( $1^{\text {st }}$ of January-2012 to $31^{\text {st }}$ of December-2016), and geographic locations including worldwide, United States (US), United Kingdom (UK), Australia (Google, Google Trends, 2016). Interestingly, data were not available neither from the developing world nor from China or India. Data from Google Trends database show the extent of internet users' interest in these "research chemicals", in other words, the "electronic popularity" of these compounds, presented in the form of a percentile (0-100) scale.

The worldwide popularity (Figure 1) has found that; 25b (least popular), 25c, and 25i (most popular). Boxplot presentation indicated that $25 \mathrm{i}$ popularity is several folds more searched (popular) than the other two forms of NBOMe; are people attracted to what can kill them! Furthermore, there are discernible statistical outliers in each one of the three, these represent a sharp increment in the searched NBOMe over time; the most prominent of these are seen in June-2013 and October-2014, and there has been a rise in NBOMe-related in intoxications and fatalities soon after each of these as seen in the combo graph (Figure 1). To be concluded, there is a rise in the popularity for the period from January-2012 to June-2013, with a subsequent decline for the period that follows. Nevertheless, the popularity of $25 \mathrm{~b}$ seems to be almost constant over time, unlike that of $25 \mathrm{c}$ and $25 \mathrm{i}$. These data (worldwide popularity of NBOMe) were also correlated with cases of intoxications and deaths (Figure 1); these cases were verified from drug fora and PubMed-Medline database (Figure 1 and 2). It was unforeseen that these incidents (of intoxications and death) run almost in parallel with the NBOMe popularity as retrieved via Google Trends. 


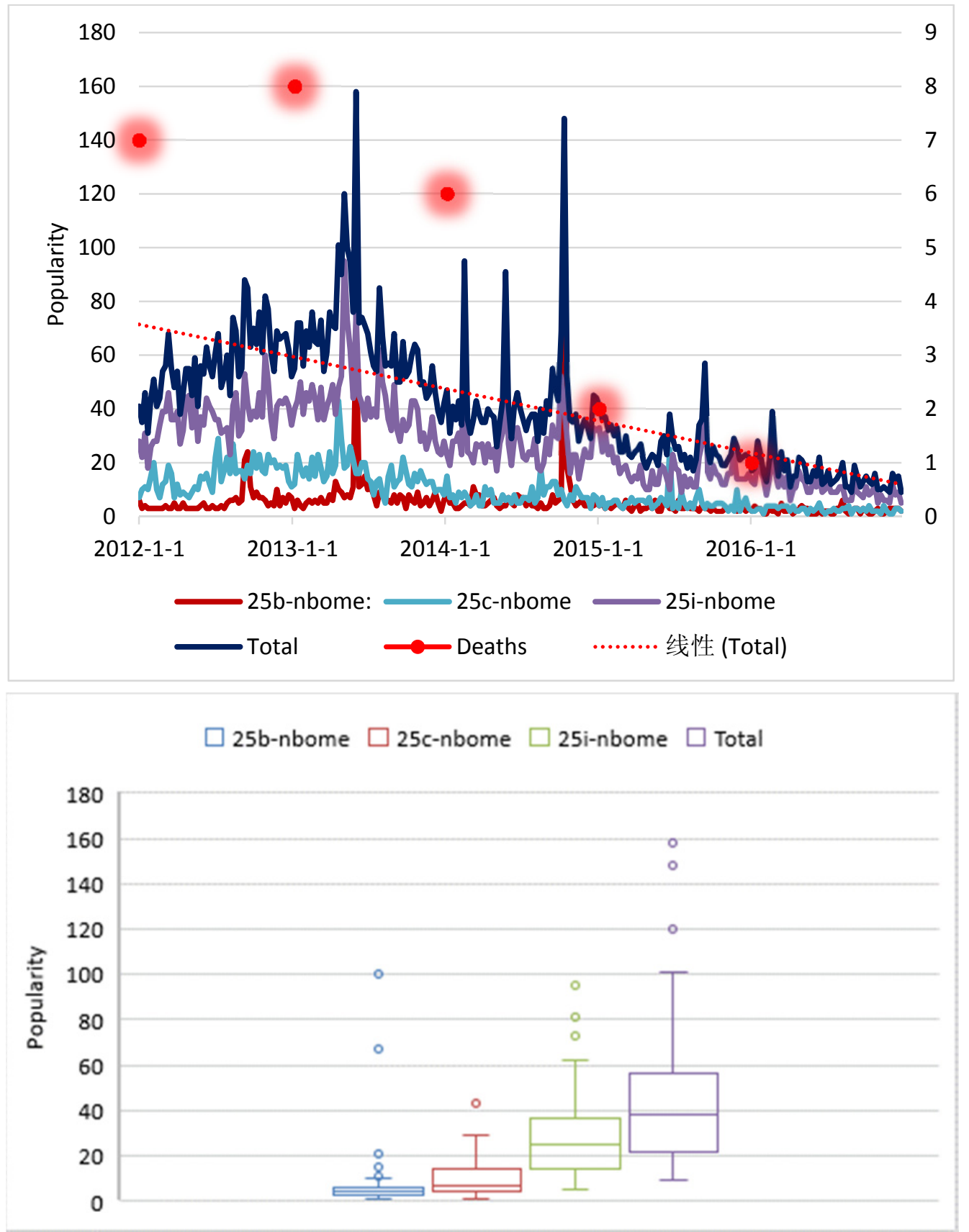

Figure 1. NBOMe Popularity on the Surface Web: Combo graph of Intoxications-Deaths and Trends' data (Google Trends), and Boxplot presentation (below) 


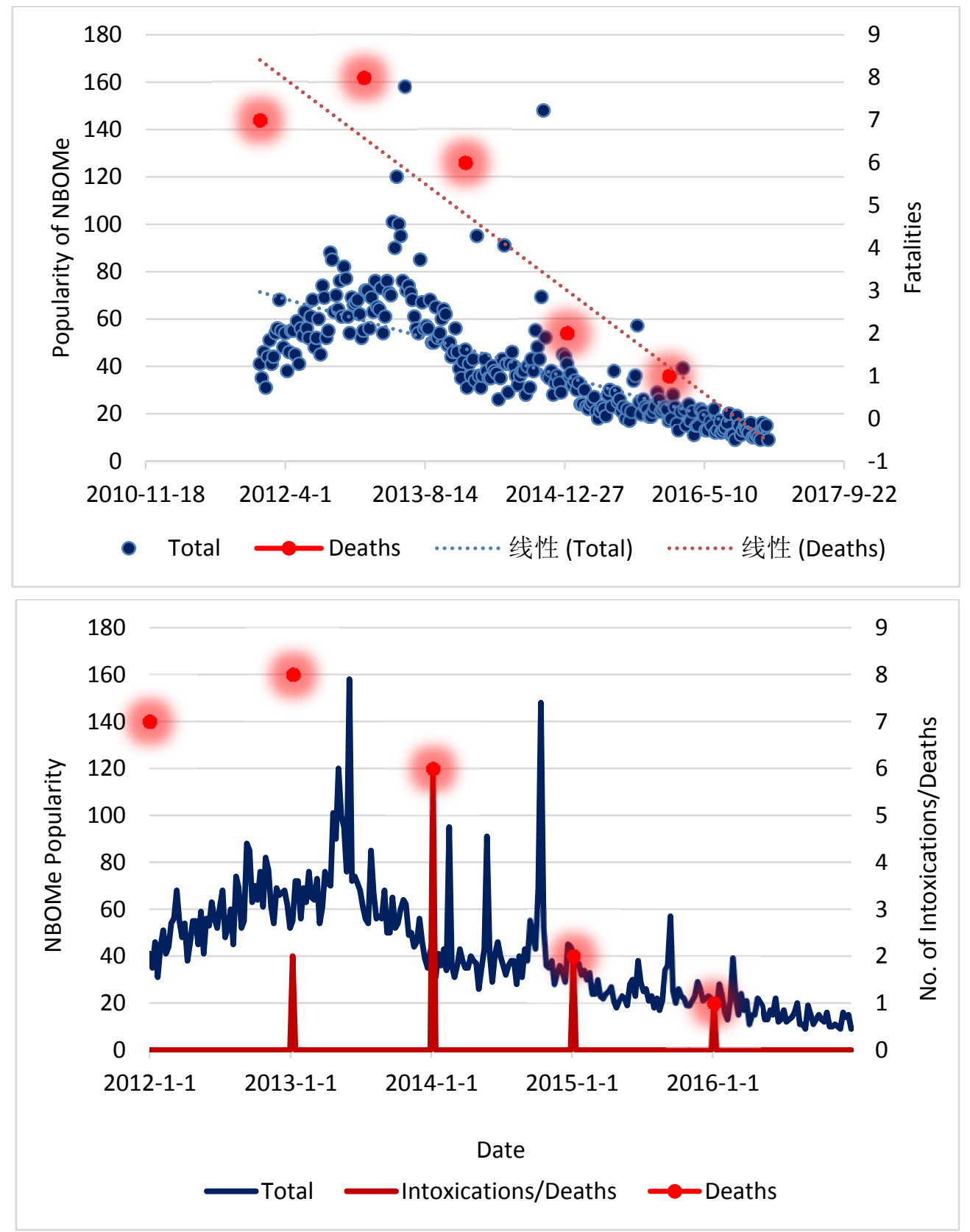

Figure 2. Combo Graphical Presentation: NBOMe popularity on the surface web versus fatalities reported in drug fora (chart above), and NBOMe popularity versus fatalities reported in PubMed-Medline versus intoxications/deaths reported in drug fora (chart below)

The popularity in of NBOMe in the US seems to follow a very similar pattern to the pattern seen in the global (worldwide) analysis. There has been a sharp increment in popularity in September-2012, April-2013, and May-2014. Similarly, the intoxication-death incidents also follow the historical (chronological) change in NBOMe popularity. It seems that the US has the greatest effect on the worldwide NBOMe popularity, In fact, it appears that the US determine the overall pattern of the searched NBOMe over the internet (surface web), while the UK rank $2^{\text {nd }}$ and Australia rank $3^{\text {rd }}$. Possibly, there are several factors behind this pattern, including demographics, cultural, and social-economics, but principally it seems that the population count in these three nations is the most critical factor in influencing this effect, the US population (325 million), UK (65 million), and Australia (24 million).

The searched NBOMe in the UK seems to follow a more erratic pattern, although $25 \mathrm{i}$ is apparently the most popular while $25 \mathrm{~b}$ is the least popular (same as the US). However, the $25 \mathrm{i}$ popularity is slightly higher than that of $25 \mathrm{c}$ and 25b. The sharp incremental rise occurred in for the period June to August-2012, January-2013, 
March-2013, June-2013, August-2013, then there is a significant decline for the period that follows and to this current date. In Australia, the pattern seems to be more consistent than that of the UK, $25 \mathrm{i}$ is also the most popular while $25 \mathrm{~b}$ and $25 \mathrm{c}$ are of lower and comparable popularity (to each other). This pattern is almost consistent for the entire period from 2012 to 2016, although a significant (very sharp) sharp rise occurred in May and June-2016.

Auxiliary individual analyses for each of the three NBOMe variants were also done. The $25 \mathrm{~b}$ popularity seems to be most popular in the UK (almost 2-3 folds more than that of the US), and the least popular in Australia. Statistical outliers can be easily visualised in a boxplot, an incremental rise in NBOMe popularity in September-2012, May and June-2013, August-2013; this appears to be followed by a subsequent abrupt decline in an almost persistent pattern to this current date. The $25 \mathrm{c}$ analyses have shown that it is most popular in the US, and least popular in Australia, although the popularity is comparable (very close to each other) in both quantity and direction over time. There has been a sharp incremental rise in popularity in July-2012, August-2012, April-2013, Septembre-2013, August-2014, and June and July-2014. The 25i analyses have shown that it is the most popular in the US and least popular in Australia, the popularity of 25i in Australia was much less than that of the UK as seen in the Boxplot, statistical outliers are also seen, and these correspond to incremental rise in popularity specifically in April-2012, May-2013, July-2013, September-2015; this was followed by a sharp decline until the current date. There is also some more significant (remarkable) rise in popularity of $25 \mathrm{i}$ in September and October-2012, April-2013, June-2013, and May-2014. Additionally, it has been mentioned formerly that the 25i-NBOMe is responsible for the vast majority of cases of intoxications and fatalities. When these catastrophes are correlated with the $25 \mathrm{i}$ popularity, it is conspicuous that there is a pattern of correlation in between the two trends.

\subsection{Changes in Trends}

The inferential statistics (t-test and ANOVA test) for the popularity of NBOMe for the period 2012-2016, do not show any statistically significant change in trends (popularity of NBOMe on the surface web) between any given year and the year next to it (Figure 3). However, there has been some degree of difference (as indicated by the p-values) across a longer time span, for example in the UK and for the period 2013-2016 (0.079), and for the period 2012-2016 (0.066). Similarly, in Australia for the period 2013-2015 (0.089), and for the period 2013-2016 (0.055). These values are considered significant at an alpha value of $0.10(90 \% \mathrm{CI})$ and should be analysed in the context of the overall NBOMe trends (Figure 2 and 3). Besides, there has also been less pronounced "significant" change in the trends, these changes existed: worldwide and for the periods 2012-2016 (0.27) and 2013-2016 (0.24), in the US for the periods 2012-2016 (0.22), 2012-2015 (0.29), 2013-2015 (0.25), 2013-2016 (0.17), and 2014-2016 (0.20), in the UK for the periods 2012-2014 (0.23), 2012-2015 (0.13), 2013-2014 (0.22), and 2013-2015 (0.13), and in Australia for the periods 2012-2016 (0.20), 2013-2014 (0.18), and 2014-2016 (0.11). However, all these $p$-values are not significant, unless an alpha value of 0.20 or 0.30 is considered $(70 \%$ and $80 \%$ $\mathrm{CI})$, which indicates an unreliable confidence interval for a precise statistical inference. To summarise, there has an incremented public interest in NBOMe from 2012 to 2013-2015; this was later followed by an overall decline towards our current day. These changes were not homogeneous worldwide. It is also enthralling to denote that this pattern of change in trends has been almost simultaneous to the reported cases of intoxications and death (Table 2, Figures 1 and 2). The cases of the correlated morbidities and mortalities have been analysed from the published literature and were indexed in PubMed-Medline database and the online drug fora. 
Table 2. NBOMe-related Cases of Intoxications and Fatalities: Summary of Reports of Interest

\begin{tabular}{|c|c|c|c|c|c|c|c|}
\hline Paper & $\begin{array}{l}\text { Date of } \\
\text { Submission }\end{array}$ & $\begin{array}{l}\text { Individual's } \\
\text { Age and } \\
\text { Gender }\end{array}$ & Country & $\begin{array}{l}\text { Type of } \\
\text { NBOMe }\end{array}$ & $\begin{array}{l}\text { Serum/Blood } \\
\text { Concentration }\end{array}$ & Polypharmacy & Life Status \\
\hline $\begin{array}{l}\text { Kueppers } \\
\text { and Cooke, } \\
2015\end{array}$ & $11-2014$ & $23 \mathrm{~F}$ & Australia & $25 \mathrm{I}$ & $28 \mu \mathrm{g} / 1$ & Yes & Death \\
\hline $\begin{array}{l}\text { Rose et al., } \\
2013\end{array}$ & 03-2013* & $18 \mathrm{M}$ & US & $25 \mathrm{I}$ & $0.76 \mathrm{ng} / \mathrm{ml}$ & Yes & Intoxication \\
\hline $\begin{array}{l}\text { Lowe et al., } \\
2015\end{array}$ & $10-2015^{*}$ & $15 \mathrm{M}$ & US & $25 \mathrm{I}$ & $0.76 \mathrm{ng} / \mathrm{ml}$ & Yes & Death \\
\hline $\begin{array}{l}\text { Suzuki et al., } \\
2014\end{array}$ & 11-2014* & $18 \mathrm{M}$ & US & $25 \mathrm{I}$ & $34 \mathrm{pcg} / \mathrm{ml}$ & Yes & $\begin{array}{l}\text { Intoxication/Suicidal } \\
\text { Attempt? }\end{array}$ \\
\hline $\begin{array}{l}\text { Byard et al., } \\
2016\end{array}$ & $11-2016^{*}$ & $19 \mathrm{M}$ & Australia & $25 \mathrm{~B}$ & $6 \mu \mathrm{g} / 1$ & Yes & Death \\
\hline $\begin{array}{l}\text { Andreasen et } \\
\text { al., } 2015\end{array}$ & $12-2014$ & $22 \mathrm{M}$ & Denmark & $25 \mathrm{C}$ & $0.60 \mu \mathrm{g} / \mathrm{kg}$ & Yes & Death \\
\hline \multirow{2}{*}{$\begin{array}{l}\text { Shanks et } \\
\text { al., } 2015\end{array}$} & \multirow{2}{*}{$11-2015^{*}$} & $18 \mathrm{M}$ & US & $25 \mathrm{~B}$ & $1.59 \mathrm{ng} / \mathrm{ml}$ & Yes & \multirow{2}{*}{ Death } \\
\hline & & $16 \mathrm{M}$ & US & $25 \mathrm{I}$ & $19.8 \mathrm{ng} / \mathrm{ml}$ & No & \\
\hline \multirow{2}{*}{$\begin{array}{l}\text { Walterscheid } \\
\text { et al., } 2014\end{array}$} & \multirow{2}{*}{ 03-2014* } & $21 \mathrm{M}$ & US & $25 \mathrm{I}$ & Not Declared & Yes & \multirow{2}{*}{ Death } \\
\hline & & $15 \mathrm{~F}$ & US & $25 \mathrm{I}$ & Not Declared & Yes & \\
\hline $\begin{array}{l}\text { Poklis et al., } \\
2014\end{array}$ & $07-2013$ & $19 \mathrm{M}$ & US & $25 \mathrm{I}$ & $405 \mathrm{pcg} / \mathrm{ml}$ & No & Death \\
\hline \multirow{2}{*}{$\begin{array}{l}\text { Tang et al., } \\
2014\end{array}$} & \multirow[b]{2}{*}{$06-2014 *$} & $17 \mathrm{M}$ & \multirow[b]{2}{*}{ China } & $25 \mathrm{~B}$ & \multirow{2}{*}{$\begin{array}{l}0.18 \text { to } 2.78 \\
\mathrm{ng} / \mathrm{ml}\end{array}$} & Not Declared & Intoxication \\
\hline & & $31 \mathrm{M}$ & & $\begin{array}{l}25 \mathrm{~B} \\
25 \mathrm{C}\end{array}$ & & Not Declared & Intoxication \\
\hline
\end{tabular}

* Date of paper (manuscript) submission is unknown; the tabulated date is the date of publication.

$\Omega$ Reviews and case series have been excluded to avoid data overlap and duplicate reporting. 


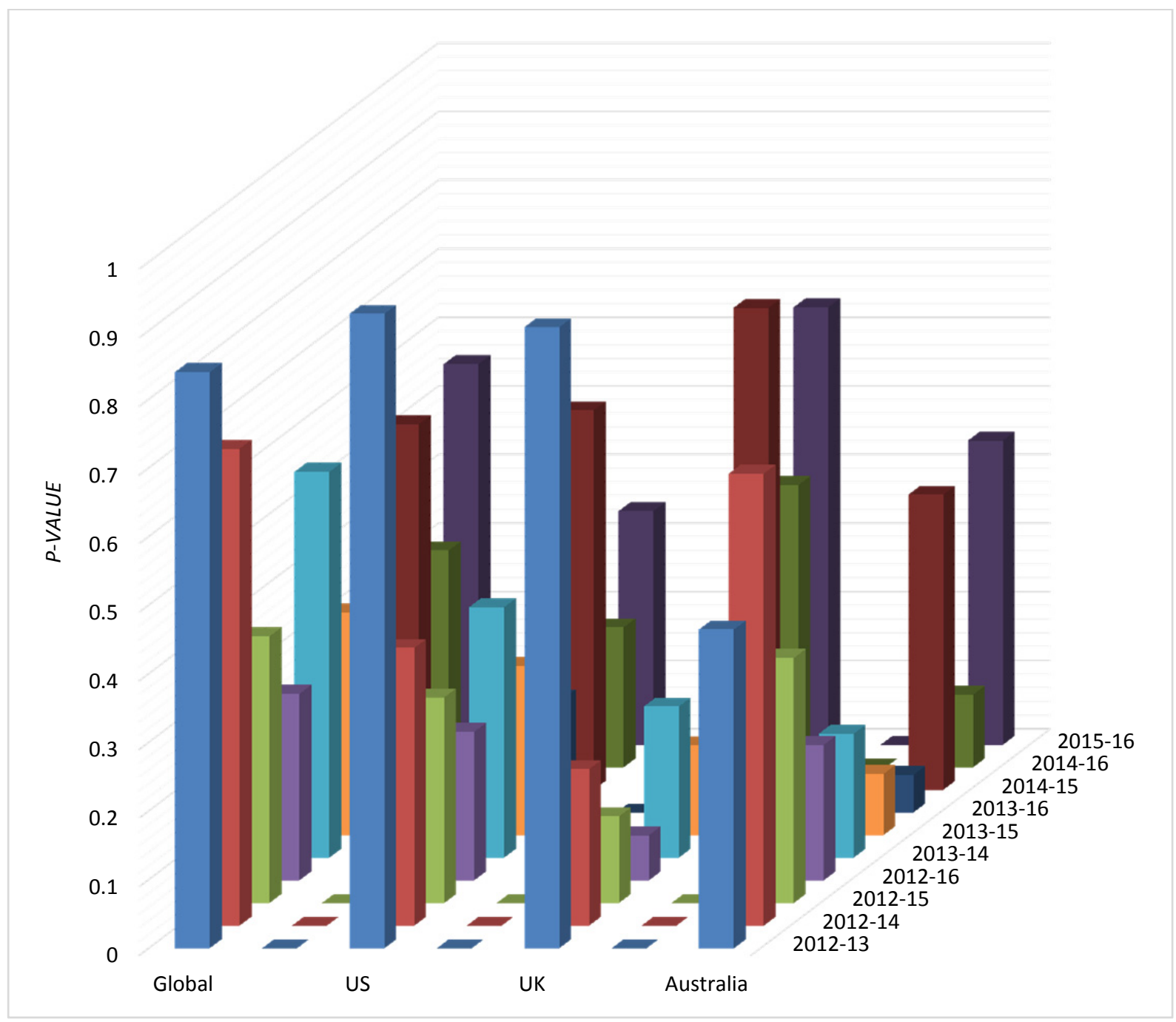

Figure 3. Three-dimensional presentation of $p$-values for change in NBOMe popularity for the period 2012-2016

\subsection{Nbome-Related Mortalities}

According to the reports of NBOMe-related fatalities (Erowid.org, 2016), there have been 24 documented incidents of death, the majority of substance users were males (79.2\%) from the United States $(87.5 \%)$ at an age ranging from 15 to 25 years, while one decedent was aged 30 representing a statistical outlier. These incidents occurred from March-2012 to January-2016, the majority were attributed to the most potent 25i-NBOMe variant $(75 \%)$, other NBOMes $(25 \mathrm{c}, 25 \mathrm{~b})$ were also incriminated $(25 \%)$, while the nature of the detected NBOMe was unknown/uncharacterized in 12.5\% of cases (Erowid.org, 2016a; Erowid.org, 2016b; Erowid.org, 2016c; Erowid.org, 2016d; Erowid.org, 2016e). The lethal dose (LD-50) is unknown for all NBOMe compounds due to the lack of animal studies. These fatalities were attributed to pharmacological-induced death $(87.5 \%)$ and behavioural-induced death $(12.5 \%)$, while the suicidal and homicidal potentials are described as unknown or yet to be confirmed (Erowid.org, 2016; Tang et al., 2014). The decedents were from multinational backgrounds including individuals from the United States, Australia, and Ireland (Erowid.org, 2016). These data are also concordant with the cases presented in this study (section 3.6) (Andreasen et al., 2015; Byard et al., 2016; Kueppers and Cooke, 2015; Lowe et al., 2015; Poklis et al., 2014; Rose et al., 2013; Shanks et al., 2015; Suzuki et al., 2014; Tang et al., 2014; Walterscheid et al., 2014). Linear regression models (Figure 2 and 3) for these incidents (intoxications and deaths) were plotted in correlation with the trends' data in an aim to reach a potential pattern of interrelationship in between the two phenomena. Moreover, the clustered-death analysis via linear regression shows an overall negative curvilinear trend for the fatalities in the period 2012-2016 $\left(R^{2}\right.$ score $\left.=0.77\right)$ and a statistically significant difference (decline) in NBOMe-related deaths in 2014-2016 ( $p$-value $=0.088$ ). 


\subsection{User Reporting About Nbome}

The majority of users describe the NBOMe experience as a fascinating experience; one enthusiastic user described his trip as 'Such Beauty. Fuck.' These three words were all I could conjure to explain what I was experiencing with the new and yet-to-be fully understood 2C-I-NBOME aka 25-I. Those three words do not even present the tip of the iceberg that is this wonderful experience from such an interesting and inspiring molecule." (Erowid.org, 2016d). NBOMe is not used as an ingredient in a pre-workout formula for gym users/athletes. It has not displaced into the world of sports performance (Erowid.org, 2016b). NBOMe has been reported to be taken to enhance sexual experiences and as a potential entactogen (empathogen), although at higher doses it gets hard for males to have or maintain an erection, as one user described "it gets difficult to get a boner".

Some drug fora (Quora.com, 2016; Psychonautwiki.org, 2016) provide instruction on how to use NBOMe, saying it is "not advised" to insufflate large amounts of NBOMe or to be taken in combination with selective serotonin reuptake inhibitors (SSRIs) and/or tricyclic antidepressants (TCAs), otherwise an inevitable serotonin toxidrome/syndrome will be imminent (Boyer and Shannon, 2005; Haberzettl et al., 2013; Psychonautwiki.org, 2016). Besides, NBOMe (particularly the 25i-NBOMe) can significantly elevate the blood pressure and exceptionally in individuals with already-established hypertension (Quora.com, 2016; Hare Krishna, 2016; Wood et al., 2015).

NBOMe Powders are considered to be more dangerous (compared to blotters) as they are not "well-calibrated", while NBOMe blotters are known to induce "psychedelic trip" at doses as low as $300 \mu \mathrm{g}(0.3 \mathrm{gm})$, and seizures and/or other features of intoxication at $1.5 \mathrm{gm}$, in addition, idiosyncratic reactions can occur at any dose, some (ab)users advise against the 25i variant and to try the least potent 25b (Erowid.org, 2016d; Officialbenzofury.net, 2016; Reddit.com, DrugsAMA, 2016). Additionally, there have been few contradictory (negative) opinions of NBOMe as reported by some users, "I have used several times LSD, Mushrooms, 2cb, Nbome and the experience was always the same with only negative aspects. The discomfort is such that prevents me from having any focus"; another user described a near-death experience (Bluelight.org, Hasnamus, 2016).

\subsection{Case Reporting Around Intoxication and Morbidities}

The signs and symptoms of reported intoxications with N-Bombs are merely the results of the combined features of hyperactivation of the serotonergic pathway, both centrally and peripherally, and the sympathetic autonomic nervous system, hence the most commonly reported features of intoxication are manifestations of both sympathomimetic and serotoninergic effects; these include tachycardia, hypertension, agitation and aggression, seizures and status epilepticus, hyperthermia, progressive dissociation, and drug-induced psychosis (Bersani et al., 2014; Forrester, 2014; Gee, 2015; Hill et al., 2014; Nikolaou et al., 2015; Quora.com, Hare Krishna, 2016; Rose, et al., 2015; Suzuki et al., 2014; Wood et al., 2015). The more severe cases frequently develop acute renal and liver injury or failure, rhabdomyolysis, serotoninergic syndrome (serotonin toxidrome), and sympathomimetic toxicities, multiple discrete intraparenchymal haemorrhages, cardiac failure, pulmonary oedema, and eventually death. (Andreasen et al., 2015; Byard et al., 2016; Kueppers \& Cooke, 2015; Lowe et al., 2015; Poklis et al., 2014; Rose et al., 2013; Shanks et al., 2015; Suzuki et al., 2014; Tang et al., 2014; Walterscheid et al., 2014). Serotonin toxidrome by itself can potentially produce acute toxicity involving metabolic acidosis, rhabdomyolysis, seizures, renal and liver failure, and disseminated intravascular coagulation (Bersani et al, 2014; Boyer \& Shannon, 2005; Forrester, 2014; Haberzettl et al., 2013; Nikolaou et al., 2015; Wood et al., 2015).

These cases (Table 2) represent case reports of interest, while case series and review papers were excluded to avoid an overlap or duplication of reported cases. The toxicological and postmortem investigations for the presence of an incriminated NBOMe, unveil that the almost all cases of death were caused by the $25 \mathrm{i}$ variant, although $25 \mathrm{~b}$ and 25c were also reported (Andreasen et al., 2015; Byard et al., 2016; Tang et al., 2014). These NBOMe psychedelics were highly potent that the detected serum/blood concentration was in microgram per millilitre $(\mu \mathrm{g} / \mathrm{ml})$, nanogram per millilitre $(\mathrm{ng} / \mathrm{ml})$, and astonishingly even in picogram per millilitre $(\mathrm{pg} / \mathrm{ml})$ (Poklis et al., 2014; Suzuki et al., 2014).

These substances were either used for recreational purposes, psychedelic/hallucinogenic experiences, and suicidal intentions (Suzuki et al., 2014); a couple of male-female ended in death (Walterscheid et al., 2014). Most of the (ab)users were males (84.6\%), aged 15 to 23 , although one victim of intoxication was a Chinese individual at the age of 31 years, representing a statistical outlier (Tang et al., 2014). The majority of NBOMe ab(users) were Caucasians from the United States (61.5\%), polypharmacy (poly-substance use) was found to be quite high (69.3\%), and most cases ended in death (69.3\%) despite receiving medical intervention; these fatalities were reported in 2013, 2014, 2015, and 2016. Most of these cases required admittance to emergency units and intensive care units for life support, hydration, intubation and assisted ventilation. The less severe cases of intoxication were 
actually managed using intravenous hydration, sedation with benzodiazepines (intravenous), the use of anticholinergic agents, and other symptomatic and supportive measures (Gee et al., 2016; Hill et al., 2016; Rose et al., 2012; Suzuki et al., 2015). The onset and duration of the NBOMe-induced effects largely depend on the doses and the routes of administration. Insufflation of NBOMe seems to produce more rapid and severe intoxication. Hence it is the most dangerous route of drug administration. It is also reported that in order to get the full effects of NBOMe blotter paper, it is required to be lightly chewed for at least 20 minutes (Psychonautwiki.org, 2016), while the long-lasting residual symptoms may last for several months after the substance use (Bersani et al., 2014; Bluelight.org, 2016).

\section{Conclusion}

NBOMe compounds are potent, dangerous, and psychologically active substances. It is a family of complex compounds; their potency and popularity are interlinked worldwide. Data from online drug fora and the appraised case series and case reports gave a deep insight towards the demographics of victims and decedents. Users appear to be predominantly males from the developed world, primarily from the United States, in their $2^{\text {nd }}$ or $3^{\text {rd }}$ decades of life. The majority of NBOMe (ab)users are attracted to using the most potent and a lethal form of NBOMe, the $25 \mathrm{i}$ variant. There are some limitations to this study; in relation to NBOMe popularity and interest over time, data were only collected from Google trends. However, these data are highly accurate as they reflect the use of specific and search terms by a range of millions (if not billions) of internet users and customers including users/patients, abusers (addicts), chemists, researchers, and scientists, etc. Data collected from Google trends can be erroneous in case the people use virtual private networks (VPN) and internet protocol masking (IP mask) while surfing the surface web; the magnitude of these technologies is yet to be estimated. Further, not all the cases of morbidities and mortalities have been (can be) reported in the literature, many cases were either documented in grey literature databases or not reported at all. Additionally, there could be some overlap between case series, and case reports of morbidities and mortalities, and especially for those stated in review articles. Furthermore, the exact date of the published case reports of intoxication and death could be either inaccurately reported or not reported at all; this will have some effect on the statistical analyses for correlation with trends databases. However, these dates can be roughly estimated from the time of manuscript submission to each journal. Therefore, direct communication with the authors is necessary to collect missing data (dates) whenever feasible. Additionally, some cases of individuals with morbidities and mortalities had more than one psychoactive or novel psychoactive substances (polypharmacy) detected in their biological fluids. Accordingly, NBOMe may not be the direct cause of intoxication and/or death.

There was also a lack of systematic reviews, randomised controlled trials, and experimental studies; this is due to the fact that these chemicals have been recently discovered in 2003-2004, and were recently promoted worldwide as NPS chemicals in 2011. Needless to say, data from Google trends can serve as an indicator of when to predict high incidences of "waves" of intoxication and/or fatalities, for example in association with holidays, rave events, e-commerce activities, and street availability of NBOMe. These can serve as an efficient peremptory warning system, providing insightful orientation to the emergency units and intensive care units at hospitals in anticipation of such catastrophic events; the purpose is to initiate or maintain pre-specified protocols to keep these casualties to a minimum. Such protocols can be developed in collaboration with local health authorities and international organisations including the world anti-doping agency (WADA), the UNODC, and the European Monitoring Centre for Drugs and Drug Addiction (EMCDDA).

Additionally, prior studies on other NPS compounds have highlighted that noteworthiness of the chemical characterization, and the vitality to conclude the comparative chemical profile both nationally and internationally for a scientific and medico-legal attributes including legislative action; other studies have also highlighted the significance of patterns of cerebral dominance and the lateralization of brain functions in connection with these NPS (Al-Hadithi et al., 2016; Al-Imam, 2017b). Finally, the diffusion of NBOMe on the deep web was not assessed, and it is beyond the scope of this study. Nevertheless, the role of the deep web in the diffusion and e-commerce of these NPS is never to be ignored (Google, Deeperweb.com, 2016; TOR2WEB, 2016; Van Hout and Hearne, 2017)

\section{Competing Interests Statement}

The authors have no conflict of interest to be declared.

\section{Source of Funding}

This study was entirely self-funded. 


\section{References}

Al-Hadithi, N., Al-Imam, A., Irfan, M., Khalaf, M., \& Al-Khafaji, S. (2016). The relation between cerebral dominance and visual analytic skills in Iraqi medical students, a cross sectional analysis. Asian Journal of Medical Sciences, 7(6), 47-52. https://doi.org/10.3126/ajms.v7i6.15205

Al-Imam, A. (2017a). Could Hallucinogens Induce Permanent Pupillary Changes in (Ab) users? A Case Report from New Zealand. Case Reports in Neurological Medicine, 2017. https://doi.org/10.1155/2017/2503762

Al-Imam, A. (2017b). The relation between cerebral dominance and visual analytic skills in Iraqi Medical students, a cross sectional analysis. Journal of the Anatomical Society of India, 66(1), 42-43. https://doi.org/10.1016/j.jasi.2017.08.136

AL-Imam, A., Santacroce, R., Roman - Urrestarazu, A., Chilcott, R., Bersani, G., Martinotti, G., \& Corazza, O. (2017). Captagon: use and trade in the Middle East. Human Psychopharmacology: Clinical and Experimental, $32(3)$.

Al-Imam, A., Simonato, A. P., \& Corazza, O. (2016). Haloperidol, an old antipsychotic with potential use by NPS users in Iraq. Research and Advances in Psychiatry, 3(3), 81-84. Retrieved from https://www.rapjournal.eu/materiale_cic/948_3_3/8031_haloperidol/article.htm

Andreasen, M. F., Telving, R., Rosendal, I., Eg, M. B., Hasselstrøm, J. B., \& Andersen, L. V. (2015). A fatal poisoning involving 25C-NBOMe. Forensic science international, 251, e1-e8. https://doi.org/10.1016/j.forsciint.2015.03.012

Bersani, F. S., Corazza, O., Albano, G., Valeriani, G., Santacroce, R., Bolzan Mariotti Posocco, F., ... \& Schifano, F. (2014). 25C-NBOMe: preliminary data on pharmacology, psychoactive effects, and toxicity of a new potent and dangerous hallucinogenic drug. BioMed Research International, 2014. https://doi.org/10.1155/2014/734749

Better Value Healthcare Ltd. Critical Appraisal Skills Programme (CASP). Retrieved 28 October, 2016, from http://www.casp-uk.net/

Bluelight.org, Hasnamus. Psycedelics. Retrieved 31 December, 2016, from http://bluelight.org/vb/threads/811234-Psycedelics?highlight=nbome

Bluelight.org. Retrieved 25 December, 2016, from http://bluelight.org/vb/forum.php

Bluelight.org. List of Nbome deaths. Retrieved 28 October, 2016, from http://www.bluelight.org/vb/threads/690574-List-of-Nbomedeaths

Boyer, E. W., \& Shannon, M. (2005). The serotonin syndrome. New England Journal of Medicine, 352(11), 1112-1120.https://doi.org/10.1056/NEJMra041867

Byard, R. W., Cox, M., \& Stockham, P. (2016). Blunt craniofacial trauma as a manifestation of excited delirium caused by new psychoactive substances. Journal of forensic sciences, 61(6), 1546-1548. https://doi.org/10.1111/1556-4029.13212

Drugfreeworld.org. WHAT IS N-BOMB? Retrieved 13 October, 2016, from http://www.drugfreeworld.org/drugfacts/synthetic/what-is-n-bomb.html

Drugs-forum.com. Retrieved 28 December, 2016 from https://drugs-forum.com/index.php

DrugWiseUK. NPS Come of Age: A UK overview. Retrieved 16 October, 2016, from http://www.drugwise.org.uk/nps-come-of-age-a-uk-overview/ (accessed).

Erowid.org. 25C-NBOMe (2C-C-NBOMe) Fatalities / Deaths. Retrieved 29 December, 2016, from https://www.erowid.org/chemicals/2cc_nbome/2cc_nbome_death.shtml

Erowid.org. 25I-NBOMe (2C-I-NBOMe) Fatalities / Deaths. Retrieved 29 December, 2016, from https://www.erowid.org/chemicals/2ci_nbome/2ci_nbome_death.shtml

Erowid.org. Retrieved 28 December, 2016, from https://www.erowid.org/

Erowid.org. NBOMe Series Reports. Retrieved 29 December, 2016 from https://erowid.org/experiences/subs/exp_NBOMe_Series.shtml

Erowid.org. Other or Unknown NBOMe Compound Fatalities / Deaths. Retrieved 29 December, 2016, from https://www.erowid.org/chemicals/nbome/nbome_death.shtml

Forrester, M. B. (2014). NBOMe designer drug exposures reported to Texas poison centers. Journal of addictive 
diseases, 33(3), 196-201. https://doi.org/10.1080/10550887.2014.950027

Gee, P., Schep, L. J., Jensen, B. P., Moore, G., \& Barrington, S. (2016). Case series: toxicity from 25B-NBOMea cluster of N-bomb cases. Clinical Toxicology, 54(2), 141-146. https://doi.org/10.3109/15563650.2015.1115056

Google. 25b-nbome,25c-nbome,25i-nbome. Retrieved 20 December, 2016, from https://www.google.com/trends/explore?date=all\&q=25b-nbome,25c-nbome,25i-nbome

Google. Deeper Web. Retrieved 10 September 2016 from http://deeperweb.com/

Google. Google Trends. Retrieved 10 September, 2016 from https://www.google.com/trends/

Haberzettl, R., Bert, B., Fink, H., \& Fox, M. A. (2013). Animal models of the serotonin syndrome: a systematic review. Behavioural brain research, 256, 328-345. https://doi.org/10.1016/j.bbr.2013.08.045

Heim, R. (2004). Synthese und pharmakologie potenter 5-HT 2A-rezeptoragonisten mit N-2-methoxybenzyl-partialstruktur (Doctoral dissertation, Freie Universität Berlin).

Hill, S. L., Doris, T., Gurung, S., Katebe, S., Lomas, A., Dunn, M., ... \& Thomas, S. H. (2013). Severe clinical toxicity associated with analytically confirmed recreational use of 25I-NBOMe: case series. Clinical Toxicology, 51(6), 487-492. https://doi.org/10.3109/15563650.2013.802795

Kueppers, V. B., \& Cooke, C. T. (2015). 25I-NBOMe related death in Australia: a case report. Forensic science international, 249, e15-e18. https://doi.org/10.1016/j.forsciint.2015.02.010

Lowe, L. M., Peterson, B. L., \& Couper, F. J. (2015). A case review of the first analytically confirmed 25I-NBOMe-related death in Washington State. Journal of analytical toxicology, 39(8), 668-671. https://doi.org/10.1093/jat/bkv092

Nikolaou, P., Papoutsis, I., Stefanidou, M., Spiliopoulou, C., \& Athanaselis, S. (2015). 2C-I-NBOMe, an "N-bomb" that kills with "Smiles". Toxicological and legislative aspects. Drug and chemical toxicology, 38(1), 113-119. https://doi.org/10.3109/01480545.2014.911882

Novel Psychoactive Treatment UK Network (NEPTUNE). Guidance on the Clinical Management of Acute and Chronic Harms of Club Drugs and Novel Psychoactive Substances. Retrieved 17 October, 2016, from http://neptune-clinical-guidance.co.uk/wp-content/uploads/2015/03/NEPTUNE-Guidance-March-2015.pdf

Officialbenzofury.net. Retrieved 28 December, 2016 from http://officialbenzofury.net/

Open Grey. System for Information on Grey Literature in Europe. Retrieved 10 September, 2016, from http://www.opengrey.eu/ (accessed)

Oxford Centre for Evidence-based Medicine. Levels of Evidence (March 2009). Retrieved 27 October, 2016, from http://www.cebm.net/oxford-centre-evidence-based-medicine-levels-evidence-march-2009/

Poklis, J. L., Devers, K. G., Arbefeville, E. F., Pearson, J. M., Houston, E., \& Poklis, A. (2014). Postmortem detection of 25I-NBOMe [2-(4-iodo-2, 5-dimethoxyphenyl)-N-[(2-methoxyphenyl) methyl] ethanamine] in fluids and tissues determined by high performance liquid chromatography with tandem mass spectrometry from a traumatic death. Forensic science international, 234, e14-e20. https://doi.org/10.1016/j.forsciint.2013.10.015

Prohormoneforum.com. PHF Supplements Forum. Retrieved 30 December, 2016, from http://www.prohormoneforum.com/

Psychonautwiki.org. 25x-NBOMe. Retrieved $30 \quad$ December, 2016 from https://psychonautwiki.org/w/index.php?title=25x-NBOMe\&_=

Quora.com, Hare Krishna. How much does 25I increase blood pressure?. Retrieved 30 December, 2016, from https://www.quora.com/How-much-does-25I-increase-blood-pressure

Reddit.com, DrugsAMA. r/Drugs FAQ series: NBOMe series (AKA 25x-NBOMe, 2Cx-NBOMe, Bomamines etc). $\begin{array}{llll}\text { Retrieved } & 31 & \text { December, } & 2016\end{array}$ https://www.reddit.com/r/Drugs/comments/14wua3/rdrugs_faq_series_nbome_series_aka_25xnbome/

Reddit.com. Retrieved 28 December, 2016 from https://www.reddit.com/

Rose, R. S., Cumpston, K. L., Stromberg, P. E., \& Wills, B. K. (2012, August). Severe poisoning following self-reported use of 25-I, a novel substituted amphetamine. In Clinical Toxicology (Vol. 50, No. 7, pp. 707-708). 52 New York, NY USA: Informa Healthcare. 
Rose, S. R., Poklis, J. L., \& Poklis, A. (2013). A case of 25I-NBOMe (25-I) intoxication: a new potent 5-HT2A agonist designer drug. Clinical toxicology, 51(3), 174-177. https://doi.org/10.3109/15563650.2013.772191

Shanks, K. G., Sozio, T., \& Behonick, G. S. (2015). Fatal intoxications with 25B-NBOMe and 25I-NBOMe in Indiana during 2014. Journal of analytical toxicology, 39(8), 602-606. https://doi.org/10.1093/jat/bkv058

Spink, A., \& Ozmultu, H. C. (2002). Characteristics of question format web queries: An exploratory study. Information processing \& management, 38(4), 453-471. https://doi.org/10.1016/S0306-4573(01)00042-5

Suzuki, J., Dekker, M. A., Valenti, E. S., Cruz, F. A. A., Correa, A. M., Poklis, J. L., \& Poklis, A. (2015). Toxicities associated with NBOMe ingestion - a novel class of potent hallucinogens: a review of the literature. Psychosomatics, 56(2), 129-139. https://doi.org/10.1016/j.psym.2014.11.002

Suzuki, J., Poklis, J. L., \& Poklis, A. (2014). "My friend said it was good LSD": a suicide attempt following analytically confirmed 25I-NBOMe ingestion. Journal of psychoactive drugs, 46(5), 379-382. https://doi.org/10.1080/02791072.2014.960111

Tang, M. H. Y., Ching, C. K., Tsui, M. S. H., Chu, F. K. C., \& Mak, T. W. L. (2014). Two cases of severe intoxication associated with analytically confirmed use of the novel psychoactive substances 25B-NBOMe and 25C-NBOMe. Clinical Toxicology, 52(5), 561-565. https://doi.org/10.3109/15563650.2014.909932

The National Center for Biotechnology Information. MeSH. Retrieved 10 September, 2016 from https://www.ncbi.nlm.nih.gov/mesh/

TOR2WEB. Grams. Retrieved 10 September, 2016, from https://grams7enufi7jmdl.onion.to/

United Nations Office on Drugs and Crimes. World Drug Report 2016. Retrieved from http://www.unodc.org/wdr2014/ (accessed 16 October 2016).Van Hout, MC., \& Hearne, E. (2017). New Psychoactive Substances (NPS) on cryptomarket fora: an exploratory study of characteristics of forum activity between NPS buyers and vendors. International Journal of Drug Policy. Early Online.

Walterscheid, J. P., Phillips, G. T., Lopez, A. E., Gonsoulin, M. L., Chen, H. H., \& Sanchez, L. A. (2014). Pathological findings in 2 cases of fatal 25I-NBOMe toxicity. The American journal of forensic medicine and pathology, 35(1), 20-25. https://doi.org/10.1097/PAF.0000000000000082

Wood, D. M., Sedefov, R., Cunningham, A., \& Dargan, P. I. (2015). Prevalence of use and acute toxicity associated with the use of NBOMe drugs. Clinical toxicology, 53(2), 85-92. https://doi.org/10.3109/15563650.2015.1004179

\section{Copyrights}

Copyright for this article is retained by the author(s), with first publication rights granted to the journal.

This is an open-access article distributed under the terms and conditions of the Creative Commons Attribution license (http://creativecommons.org/licenses/by/4.0/). 